\title{
"How Much is that Player in the Window? The One with the Early Birthday?' Relative Age Influences the Value of the Best Soccer Players, but Not the Best Businesspeople
}

\author{
Philip Furley $^{1 *}$, Daniel Memmert ${ }^{1}$ and Matthias Weigelt ${ }^{2}$ \\ ${ }^{1}$ Institute of Cognitive and Team/Racket Sport Research, German Sport University, Köln, Germany, ${ }^{2}$ Department Sport and \\ Health, University of Paderborn, Paderborn, Germany
}

Keywords: relative age effects, birthdate, Soccer, talent, development

OPEN ACCESS

Edited by:

Ana Bengoetxea,

Universidad del País Vasco-Euskal Herriko Unibertsitatea, Spain

Reviewed by:

Uner Tan,

Cukurova University, Turkey Jon Irazusta

University of the Basque Country,

Spain

*Correspondence:

Philip Furley

p.furley@dshs-koeln.de

Specialty section:

This article was submitted to Movement Science and Sport

Psychology,

a section of the journal

Frontiers in Psychology

Received: 26 November 2015

Accepted: 15 January 2016

Published: 02 February 2016

Citation:

Furley P, Memmert $D$ and Weigelt $M$ (2016) "How Much is that Player in the

Window? The One with the Early Birthday?" Relative Age Influences the Value of the Best Soccer Players, but

Not the Best Businesspeople.

Front. Psychol. 7:84.

doi: 10.3389/fpsyg.2016.00084
Although people in general tend to attribute success to individual merit (see e.g., Gilbert and Malone, 1995) research has shown that something as trivial as the date of a person's birth can have-under certain circumstances-a major impact on an individual's achievement. The Canadian psychologist Roger Barnsley (Barnsley et al., 1985) made the extraordinary discovery that the great majority of top-level athletes were born within the first months of the year, whereas a lot less players playing at the highest level were born later in the year (Dudink, 1994; Edwards, 1994; Cobley et al., 2009). This skewed birthdate distribution was termed Relative Age Effect. The assumed explanation for this effect was simple and had nothing to do with Astrology, but instead was attributed to the fact that children and youth athletes are divided into age-groups according to their birth date (usually with the cutoff date being the first of January). This early selection cutoff date can lead to a maturation head start of almost a year within an age group. It is further assumed that this maturation head start will result in a Matthew effect ("the rich get richer; the poor get poorer," see e.g., Merton, 1957) due to better developmental circumstances, such as better coaching, more playing and practice time. Indeed, research suggests that coaches have more favorable attitudes toward more matured players (Furley and Memmert, 2015) and that maturation advantages have the potential to translate to performance advantages (Buchheit and Mendez-Villanueva, 2014; Gastin and Bennett, 2014). As a consequence, the most successful athletes are likely to show a skewed birthdate distribution (see e.g., Helsen et al., 2012 for a recent demonstration), whereas success in other domains without early selection processes involving cutoff dates should not show a skewed birthdate distribution as individuals have equal opportunities to develop (Barnsley et al., 1985).

To date Relative Age Effects have almost exclusively been shown within high achieving cohorts, such as national teams or within the highest levels of competitive sport, while it remains unclear whether birthdates also have the potential to translate to monetary value. Therefore, we tested for Relative Age Effects within the 100 most valuable soccer players according to their 2015 CIES (Poli et al., 2015) estimated transfer values (high achievement group with early selection cutoff date) and within the 100 richest billionaires according to their Forbes Net Value (high achievement group without early selection cutoff date). See Supplemental Material and Author Note for more detail on the analyzed sample.

As expected, we found that amongst the 100 most valuable soccer players $60 \%$ were born in the first half of the year $\left(M_{\text {value }}=48.3\right.$ million $\$ ; S D_{\text {value }}=41.1$ million $\left.\$\right)$, whereas $40 \%\left(M_{\text {value }}=39.8\right.$ million \$; $S D_{\text {value }}=15.1$ million) were born in the second half, which differed significantly form the expected even distribution $\left[\chi_{(1, N=100)}^{2}=4.000 ; p=0.023\right.$, one-tailed; $O R=1.50(0.86,2.62)$; 


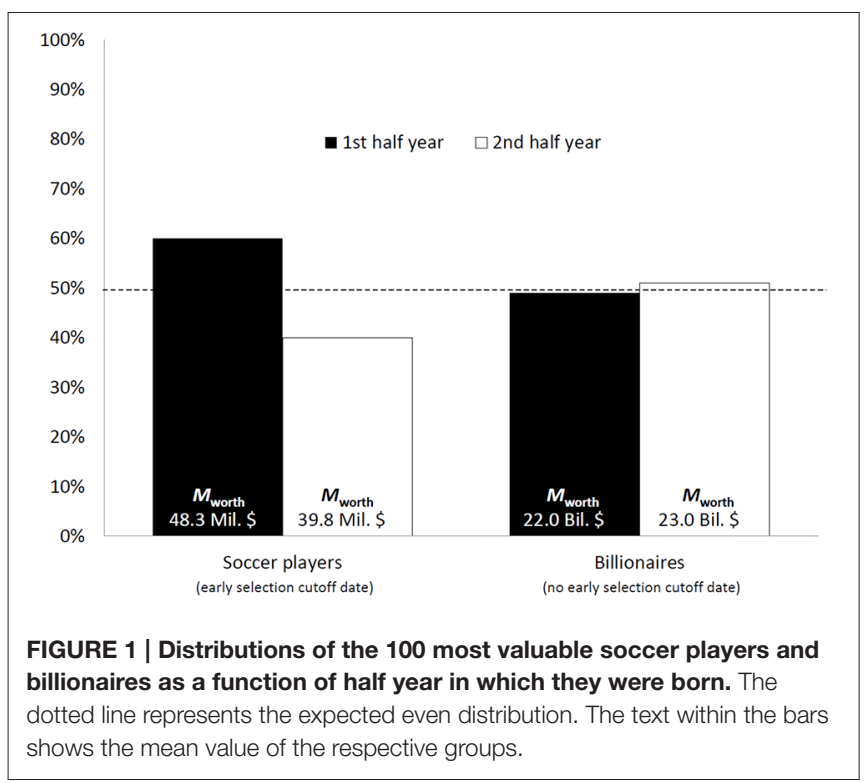

see Figure 1]. Although, players born in the first half of the year were worth approximately 8 Million $\$$ more, this effect only approached significance $\left[t_{(80.380)}=1.472, p=0.07\right.$, onetailed; $d=0.30(-0.10,0.70)]$. Importantly, no such skewed distribution was evident amongst the 100 highest ranked Forbes billionaires $\left[x_{(1, N=100)}^{2}=0.040 ; p=0.841\right.$, two-tailed; $O R$ $=0.96(0.55,1.67)]$ with $49 \%$ being born in the first half year $\left(M_{\text {netvalue }}=22.0\right.$ billion\$; $S D_{\text {netvalue }}=13.3$ billion $)$ and $51 \%$ $\left(M_{\text {netvalue }}=23.0\right.$ billion\$; $S D_{\text {netvalue }}=14.3$ billion $)$ in the second half year. Comparative analysis of both the soccer and the Forbes distribution revealed a significant difference between the birthdate distributions of the 100 most valuable - in monetary terms-soccer players and businesspeople $\left[\chi_{(1, N=100)}^{2}=6.829\right.$; $p=0.008$, one-tailed; $O R=1.56(0.89,2.73)]$.

The present analysis shows that birthdates-under certain circumstances (early selection cutoff dates) - not only have the potential to open up gates to high achieving cohorts, but can actually result in higher monetary value (but see Ashworth and Heyndels, 2007, for differences in actual earnings). While the division of children into age groups based on their birth-date has the well-meant intention to provide equal opportunities for participation and success, paradoxically this is not the case as there is a systematic exclusion of children born further away from

\section{REFERENCES}

Ashworth, J., and Heyndels, B. (2007). Selection bias and peer effects in team sports the effect of age grouping on earnings of German soccer players. J. Sports Econom. 8, 355-377. doi: 10.1177/1527002506287695

Barnsley, R. H., Thompson, A. H., and Barnsley, P. E. (1985). Hockey success and birthdate: The relative age effect. Phys. Health Educ. J. 51, 23-28.

Buchheit, M., and Mendez-Villanueva, A. (2014). Effects of age, maturity and body dimensions on match running performance in highly trained under-15 soccer players. J. Sports Sci. 32, 1271-1278. doi: 10.1080/02640414.2014.884721

Cobley, S., Baker, J., Wattie, N., and McKenna, J. (2009). Annual age-grouping and athlete development. Sports Med. 39, 235-256. doi: 10.2165/00007256200939030-00005 the cutoff date (usually later in the year if the cutoff date is the 1st of January). Here, it is important to note that Relative Age Effects have also been found in the broader educational system (Pidgeon, 1965), albeit the pattern is not very consistent across studies (e.g., Jeronimus et al., 2015 for a recent investigation). Of further relevance, Matsubayashi and Ueda (2015) argued that relative younger students seem to take less desirable career paths that might be associated with poorer psychological health compared to students with a relative age advantage. In this respect, we hope to add a further line of argumentation against highly-selective developmental and education systems beginning at early ages based on birthdates as people in domains that arguably are not affected (e.g., business) by early selection cutoff dates have the potential of doing equally well.

Taken together, early selection cutoff dates have broad implications that need to be taken seriously by political decision makers in order to meet the goal of providing equal opportunities to people.

\section{AUTHOR NOTE}

As the estimated transfer values for the soccer players were published as ranges, we calculated the mean of the range for the conducted analyses. Two birthdates could not be obtained from the top 100 Forbes list (rank 32 and 52). Further, ranks 58, 69, and 80 were siblings with diverging birthdates and were therefore not included in the analyses. In order to have an equal sample size to the soccer players, we filled up the list with the subsequent ranks until rank 105.

\section{AUTHOR CONTRIBUTIONS}

PF, DM, MW developed the study concept, and all authors contributed to the design and collected the data. PF analyzed it in collaboration with DM. PF wrote the first draft of the manuscript, and DM and MW helped edit and revise it. All authors approved the final, submitted version of the manuscript.

\section{SUPPLEMENTARY MATERIAL}

The Supplementary Material for this article can be found online at: http://journal.frontiersin.org/article/10.3389/fpsyg. 2016.00084

Dudink, A. (1994). Birth date and sporting success. Nature 368, 592. doi: $10.1038 / 368592 \mathrm{a} 0$

Edwards, S. (1994). Born too late to win? Nature 370, 186. doi: 10.1038/370186a0

Furley, P., and Memmert, D. (2015). Coaches' implicit associations between size and giftedness: Implications for the Relative Age Effect. J. Sports Sci. 34, 459-466. doi: 10.1080/02640414.2015.1061198

Gastin, P. B., and Bennett, G. (2014). Late maturers at a performance disadvantage to their more mature peers in junior Australian football. J. Sports Sci. 32, 563-571. doi: 10.1080/02640414.2013.843016

Gilbert, D. T., and Malone, P. S. (1995). The correspondence bias. Psychol. Bull. 117, 21-38. doi: 10.1037/0033-2909.117.1.21

Helsen, W. F., Baker, J., Michiels, S., Schorer, J., Van Winckel, J., and Williams, A. M. (2012). The relative age effect in 
European professional soccer: Did ten years of research make any difference? J. Sports Sci. 30, 1665-1671. doi: 10.1080/02640414.2012. 721929

Jeronimus, B. F., Stavrakakis, N., Veenstra, R., and Oldehinkel, A. J. (2015). Relative age effects in dutch adolescents: concurrent and prospective analyses. PLoS ONE 10: e0128856. doi:10.1371/journal.pone. 0128856

Matsubayashi, T., and Ueda, M. (2015). Relative age in school and suicide among young individuals in Japan: a regression discontinuity approach. PLoS ONE 10:e0135349. doi:10.1371/journal.pone.0135349

Merton, R. K. (1957). Social Theory and Social Structure. Glencoe, IL: The Free Press.

Pidgeon, D. A. (1965). Date of birth and scholastic performance. Educ. Res. 8, 3-7. doi: $10.1080 / 0013188650080101$
Poli, R., Ravenel, L., and Besson, R. (2015, June). Transfer values and probabilities. CIES Football Observatory Monthly Report, 6, 1-11.

Conflict of Interest Statement: The authors declare that the research was conducted in the absence of any commercial or financial relationships that could be construed as a potential conflict of interest.

Copyright $(\odot 2016$ Furley, Memmert and Weigelt. This is an open-access article distributed under the terms of the Creative Commons Attribution License (CC $B Y)$. The use, distribution or reproduction in other forums is permitted, provided the original author(s) or licensor are credited and that the original publication in this journal is cited, in accordance with accepted academic practice. No use, distribution or reproduction is permitted which does not comply with these terms. 